OPEN ACCESS

Edited by:

Songwen Tan,

Central South University, China

Reviewed by:

Li Genlin,

University of South China, China Jiangang Liu,

The Second Affiliated Hospital of

Shandong First Medical

University, China

${ }^{*}$ Correspondence:

Zhongsheng Tong

15222566488@163.com

tThese authors share first authorship

Specialty section This article was submitted to

Visceral Surgery,

a section of the journal

Frontiers in Surgery

Received: 27 December 2021 Accepted: 17 January 2022

Published: 15 February 2022

Citation:

He L, Wang $X$, Liu $X$, Jia Y, Zhao W, Jia $X$, Zhu $Y$, Meng $W$ and Tong $Z$

(2022) Analysis of Clinical

Characteristics, Treatment, and

Prognostic Factors of 106 Breast

Cancer Patients With Solitary

Pulmonary Nodules.

Front. Surg. 9:843913.

doi: 10.3389/fsurg.2022.843913

\section{Analysis of Clinical Characteristics, Treatment, and Prognostic Factors of 106 Breast Cancer Patients With Solitary Pulmonary Nodules}

\author{
Lihong $\mathrm{He}^{\dagger}$, Xiaorui Wang ${ }^{\dagger}$, Xiaodong Liu, Yongsheng Jia, Weipeng Zhao, Xiaochen Jia, \\ Yuehong Zhu, Wenjing Meng and Zhongsheng Tong* \\ Key Laboratory of Cancer Prevention and Therapy, Department of Breast Cancer, National Research Center for Cancer, \\ Tianjin Medical University Cancer Institute and Hospital, Tianjin, China
}

Objective: The clinical features of solitary pulmonary nodules (SPN) in breast cancer patients were retrospectively analyzed, and the clinical features of primary lung cancer $(\mathrm{PLC})$ and metastatic pulmonary breast cancer (MBC) in breast cancer patients were compared, and the treatment plan, curative effect and influencing factors were analyzed.

Methods: The clinical data of 106 patients of SPN combined with breast cancer surgery in our hospital from January 2015 to June 2020 were analyzed. There were 65 patients of PLC and 41 patients of MBC. Record the characteristics of the primary breast cancer lesion in our patient, the interval between the initial diagnosis of breast cancer and the appearance of SPN, the previous treatment history of our patient, and the characteristics and surgical method of SPN. The survival status of all patients during the follow-up period was recorded.

Results: The onset age, interval, maximum nodule diameter, ER expression positive rate and radiotherapy history ratio of PLC patients were higher than those of MBC patients, and the lymph node positive rate and triple negative rate were lower than those of MBC patients $(P<0.05)$. Median survival was 51 months in patients with PLC and 37 months in patients with MBC. The 1, 3, and 5 year overall survival rates in patients with PLC were higher than those in patients with MBC $(P<0.05)$. Vascular tumor thrombus, SPN type and chemotherapy were all independent factors affecting the prognosis of patients with breast cancer combined with SPN $(P<0.05)$.

Conclusion: PLC patients and MBC patients have significant differences in pathological characteristics, like the onset age, interval, maximum nodule diameter, ER expression positive rate, radiotherapy history ratio, the lymph node positive rate, and triple negative rate. Septum, vascular tumor thrombus, SPN type, and chemotherapy are all independent factors that affect the curative effect of breast cancer patients with SPN. Based on the nature of SPN, it can provide reference for clinicians to decide the treatment plan, improve patients' quality of life and prolong their survival time.

Keywords: breast cancer, primary lung cancer, metastatic pulmonary breast cancer, treatment, prognosis 


\section{INTRODUCTION}

Breast cancer is one of the most common malignant tumors in women, and its incidence is extremely high (1). With the application of radiotherapy, chemotherapy, and targeted therapy, the survival time of breast cancer patients is prolonged, but the risk of secondary primary cancer is increasing gradually. Studies have shown that the primary malignant tumors secondary to breast cancer mainly include endometrial cancer, blood tumor, lung cancer, and so on (2). It is the second most common primary cancer patients with breast cancer, and the lung is also the common metastatic site of breast cancer $(3,4)$. When an isolated pulmonary nodule (SPN) is found in patients with breast cancer, it is easy to diagnose metastatic pulmonary breast cancer (MBC) clinically, and the treatment direction will be biased toward breast cancer, leading to the change of treatment choice
(5). The clinical diagnosis and treatment of $\mathrm{MBC}$ need to be differentiated, but the epidemiological and clinicopathological features of secondary lung cancer after breast cancer have not been fully revealed, and multi-center research lacks the support of big data. Therefore, when finding SPN in breast cancer patients, the first clinical problem to be solved to accurately diagnose the nature of SPN and distinguish between primary lung cancer (PLC) and MBC, which is of great significance to guide breast cancer patients and SPN patients to choose the best individualized treatment scheme $(6,7)$. In this study, we retrospectively analyzed the clinical characteristics of breast cancer patients with SPN, compared the clinical characteristics of PLC and MBC, and analyzed the efficacy of patients and the related factors affecting the prognosis of breast cancer patients with SPN, in order to provide clinical basis for the treatment and prognosis of breast cancer patients with SPN.

TABLE 1 | Comparison of clinical characteristics between patients with PLC and MBC disease ( $n, \bar{x} \pm s)$.

\begin{tabular}{|c|c|c|c|c|}
\hline Clinical pathological features & PLC $(n=65)$ & $\operatorname{MBC}(n=41)$ & $t / \chi^{2}$ value & $P$-value \\
\hline Onset age (years) & $55.42 \pm 11.08$ & $43.72 \pm 9.85$ & 5.523 & 0.027 \\
\hline Interval (years) & $5.47 \pm 1.53$ & $2.86 \pm 1.07$ & 6.542 & 0.008 \\
\hline Maximum diameter of nodule (mm) & $22.39 \pm 8.94$ patients with & $16.24 \pm 10.53$ & 3.218 & 0.042 \\
\hline Pathological type of breast cancer & & & 0.239 & 0.624 \\
\hline Invasive ductal carcinoma & $48(73.85 \%)$ & $32(78.05 \%)$ & & \\
\hline Level 1 & $12(18.46 \%)$ & $8(19.51 \%)$ & & \\
\hline Level 2 & 31 (47.69\%) & 19 (46.34\%) & & \\
\hline Level 3 & 22 (33.85\%) & 14 (34.15\%) & & \\
\hline Lymph node status & & & 6.154 & 0.013 \\
\hline Positive & $30(46.15 \%)$ & 29 (70.73\%) & & \\
\hline Negative & $23(35.38 \%)$ & $23(56.10 \%)$ & & \\
\hline PR expression & & & 0.331 & 0.566 \\
\hline Positive & 37 (56.92\%) & $21(51.22 \%)$ & & \\
\hline Negative & $28(43.08 \%)$ & $20(48.78 \%)$ & & \\
\hline HER-2 expression & & & 0.095 & 0.758 \\
\hline Positive & $25(38.46 \%)$ & $17(41.46 \%)$ & & \\
\hline Negative & $40(61.54 \%)$ & $24(58.54 \%)$ & & \\
\hline Triple negative & & & 4.352 & 0.037 \\
\hline Yes & $12(18.46 \%)$ & 15 (36.59\%) & & \\
\hline No & $53(81.54 \%)$ & $26(63.41 \%)$ & & \\
\hline History of radiotherapy & & & 5.221 & 0.029 \\
\hline No & $21(32.31 \%)$ & 19 (46.34\%) & & \\
\hline
\end{tabular}


TABLE 2 | Comparison of overall survival rates between patients with PLC and $\mathrm{MBC}$ disease ( $n, \%)$.

\begin{tabular}{lccc}
\hline Group & \multicolumn{3}{c}{ Overall survival rate } \\
\cline { 2 - 4 } & 1 year & 3 years & 5 years \\
\hline PLC $(n=65)$ & $59(90.77 \%)$ & $47(72.31 \%)$ & $20(30.77 \%)$ \\
MBC $(n=41)$ & $34(82.93 \%)$ & $17(41.46 \%)$ & $8(19.51 \%)$ \\
$\chi^{2}$-value & 3.437 & 5.998 & 5.512 \\
$P$-value & 0.041 & 0.012 & 0.016 \\
\hline
\end{tabular}

\section{DATA AND METHODS}

\section{General Information}

The clinical data of 106 patients of SPN combined with breast cancer diagnosed and treated in our hospital from January 2015 to June 2020 were analyzed. All patients chose the treatment plan according to their specific condition, and they met the patient inclusion criteria.

\section{Inclusion Criteria}

SPN was found during postoperative follow-up of breast cancer, and confirmed as PLC or MBC; By biopsy or post-operative pathological examination; Breast cancer was the first primary cancer; Clinical data of diagnostic immunohistochemistry; and postoperative treatment of breast cancer were complete.

\section{Exclusion Criteria}

Benign pulmonary nodules diagnosed by pathological examination; Patients with history of metastases of other malignant tumors or other sites; Follow-up universal periodic review failed; and follow-up data was lost.

All the patients were female, and 65 patients with PLC and 41 patients with MBC were diagnosed pathologically from SPN. Among the 65 PLC patients, there were 29 patients with lung squamous cell carcinoma, 22 patients with lung adenocarcinoma, 11 patients with small cell lung cancer, and 3 patients with large cell lung cancer.

\section{Research Methods}

The characteristics of primary breast cancer lesions in our patient were recorded, including pathological type, histological grade, lymph node status, expression of estrogen receptor (ER), progesterone receptor (PR), human epidermal growth factor receptor 2 (HER-2), and vascular tumor thrombi. HER2 was determined to be negative based on 0 or + by immunohistochemistry and positive based on +++ by fluorescence in situ hybridization. ER or PR positivity is defined as the proportion of cells positive for immunohistochemical staining reaching more than $1 \%$. The triple negativity was negative for ER, PR, and HER-2. Record the interval between the initial diagnosis of breast cancer and the appearance of SPN, the previous treatment history of the patient, and the characteristics and surgical method of SPN. Patients were followed up to June 2021, and their post-treatment survival (from surgery to time of death or follow-up deadline) was recorded.

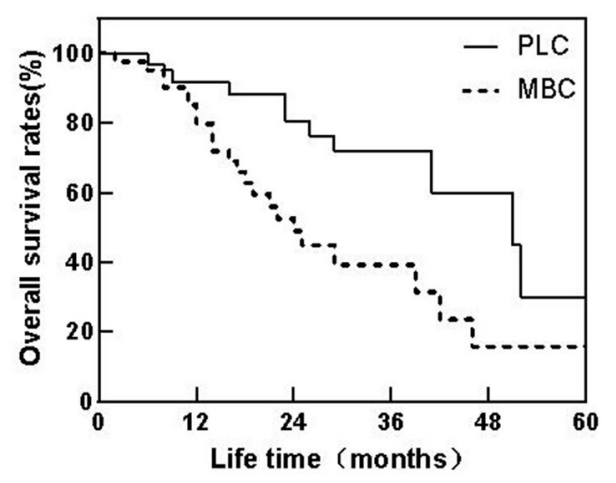

FIGURE 1 | Patient survival curves of PLC and MBC.

\section{Statistical Methods}

SPSS22.0 software was used for processing. The measurement data of experimental data were expressed as mean standard deviation $(\bar{x} \pm s)$, and the enumeration data were expressed as (\%). $t$-test was used for pairwise comparison of measurement data between groups, and $\chi^{2}$ test was used for enumeration data. Kaplan-Meier method was used to draw the survival curve. Multivariate Logisitic regression model was used to analyze the related factors affecting the postoperative efficacy of patients with breast cancer combined with SPN. The test level was $\alpha=0.05$, and $P<0.05$ indicated that the difference was statistically significant.

\section{RESULTS}

\section{Comparison of Clinical Characteristics Between Patients With PLC and MBC Disease}

The differences in age at onset, interval, maximum nodule diameter, lymph node status, ER expression, triple negative, and radiotherapy history between PLC patients and MBC patients were statistically significant $(P<0.05)$, while the differences were not statistically significant in pathological type, histological grade, PR expression, HER-2 expression, chemotherapy history, and endocrine treatment history $(P>0.05)$ as shown in Table 1.

\section{Treatment of Patients With PLC and MBC Disease}

Among 65 patients with primary liver cancer, 23 patients underwent radical lobectomy plus chemotherapy plus radiotherapy, 39 patients underwent wedge resection plus chemotherapy, and 3 patients underwent radiotherapy plus chemotherapy. Among 41 patients with MBC, 13 patients received wedge resection plus endocrine therapy, 21 patients received chemotherapy plus radiotherapy plus endocrine therapy, and seven patients received radiotherapy and chemotherapy. 
TABLE 3 | Univariate analysis of prognosis of patients with breast cancer combined with SPN ( $n$, \%).

\begin{tabular}{|c|c|c|c|c|}
\hline $\begin{array}{l}\text { Clinical } \\
\text { pathological } \\
\text { features }\end{array}$ & $\begin{array}{l}\text { Survival } \\
(n=28)\end{array}$ & $\begin{array}{l}\text { Death } \\
(n=78)\end{array}$ & $\chi^{2}$-value & $P$-value \\
\hline $\begin{array}{l}\text { Onset age } \\
\text { (years) }\end{array}$ & & & 0.394 & 0.531 \\
\hline$\geq 50$ & $17(60.71 \%)$ & 42 (53.85\%) & & \\
\hline$<50$ & 11 (39.29\%) & 36 (46.15\%) & & \\
\hline $\begin{array}{l}\text { Interval time } \\
\text { (years) }\end{array}$ & & & 10.118 & 0.001 \\
\hline$\geq 3$ & 22 (78.57\%) & 34 (43.59\%) & & \\
\hline$<3$ & 6 (21.43\%) & 44 (56.41\%) & & \\
\hline $\begin{array}{l}\text { Vascular cancer } \\
\text { thrombi }\end{array}$ & & & 13.562 & $<0.001$ \\
\hline Yes & 7 (25.00\%) & 51 (65.38\%) & & \\
\hline No & 21 (75.00\%) & 27 (34.62\%) & & \\
\hline $\begin{array}{l}\text { Pathological } \\
\text { type }\end{array}$ & & & 1.192 & 0.275 \\
\hline $\begin{array}{l}\text { Invasive ductal } \\
\text { carcinoma }\end{array}$ & 19 (67.86\%) & $61(78.21 \%)$ & & \\
\hline $\begin{array}{l}\text { Invasive lobular } \\
\text { carcinoma }\end{array}$ & 9 (32.14\%) & 17 (21.79\%) & & \\
\hline $\begin{array}{l}\text { Histological } \\
\text { grading }\end{array}$ & & & 1.088 & 0.581 \\
\hline Level 1 & 7 (25.00\%) & 13 (16.67\%) & & \\
\hline Level 2 & 13 (46.43\%) & 37 (47.44\%) & & \\
\hline Level 3 & $8(28.57 \%)$ & 28 (35.89\%) & & \\
\hline $\begin{array}{l}\text { Lymph node } \\
\text { status }\end{array}$ & & & 0.034 & 0.853 \\
\hline Positive & 16 (57.14\%) & 43 (55.13\%) & & \\
\hline Negative & 12 (42.86\%) & 35 (44.87\%) & & \\
\hline $\begin{array}{l}\text { Maximum } \\
\text { diameter of } \\
\text { nodule }(\mathrm{mm})\end{array}$ & & & 5.782 & 0.016 \\
\hline$\geq 20$ & 22 (78.57\%) & 41 (52.56\%) & & \\
\hline$<20$ & $6(21.43 \%)$ & 37 (47.44\%) & & \\
\hline Type of SPN & & & 4.639 & 0.024 \\
\hline PLC & 20 (71.43\%) & 45 (57.69\%) & & \\
\hline $\mathrm{MBC}$ & 8 (28.57\%) & 33 (42.31\%) & & \\
\hline $\begin{array}{l}\text { Surgical } \\
\text { approach }\end{array}$ & & & 0.535 & 0.464 \\
\hline Lobectomy & 10 (35.71\%) & 13 (16.67\%) & & \\
\hline $\begin{array}{l}\text { Wedge } \\
\text { resection/tumor } \\
\text { resection }\end{array}$ & 18 (64.29\%) & 34 (43.59\%) & & \\
\hline Chemotherapy & & & 5.319 & 0.021 \\
\hline Yes & 28 (100.00\%) & 65 (83.33\%) & & \\
\hline No & $0(0.00 \%)$ & 13 (16.67\%) & & \\
\hline $\begin{array}{l}\text { Endocrine } \\
\text { therapy }\end{array}$ & & & 0.063 & 0.802 \\
\hline Yes & $6(21.43 \%)$ & 15 (19.23\%) & & \\
\hline No & 22 (78.57\%) & 63 (80.77\%) & & \\
\hline
\end{tabular}

TABLE 4 | Assignment for multivariate analysis of factors.

\begin{tabular}{lcc}
\hline Factors & Variables & Assignment \\
\hline $\begin{array}{l}\text { Interval time } \\
\text { Vascular tumor } \\
\text { thrombus }\end{array}$ & X2 & $\geq 3$ years $=0,<3$ years $=1$ \\
$\begin{array}{l}\text { Maximum } \\
\text { diameter of } \\
\text { nodules } \\
\text { Type of SPN } \\
\text { Chemotherapy }\end{array}$ & X3 $=1$, No $=0$ \\
& X4 & $\geq 20 \mathrm{~mm}=0,<20 \mathrm{~mm}=1$ \\
& X5 & PLC $=0, \mathrm{MBC}=1$ \\
& & Yes $=1, \mathrm{No}=0$
\end{tabular}

\section{Prognosis of Patients With PLC and MBC Disease}

The median survival time of patients with PLC was 51 months, and the overall survival rates of 1,3 , and 5 years were $90.77,72.31$, and $30.77 \%$, respectively. The median survival time of patients with $\mathrm{MBC}$ was 37 months, and the overall survival rates of 1 , 3 , and 5 years were $82.93,41.46$, and $19.51 \%$, respectively. The median survival time of PLC patients is longer than that of MBC patients, and the Log-rank test is $P=0.034$, the difference is statistically significant. The 1,3 , and 5 years overall survival rates of patients with PLC were higher than those of patients with $\mathrm{MBC}$, and the differences were statistically significant $(P<0.05)$ as shown in Table 2, Figure 1.

\section{Univariate Analysis of Prognosis of Patients With Breast Cancer Combined With SPN}

Univariate analysis showed that the prognosis of breast cancer patients with SPN was related to the interval time, the presence or absence of vascular tumor thrombus, the maximum diameter of nodules, the type of SPN and chemotherapy $(P<0.05)$ as shown in Table 3.

\section{Analysis of Multiple Factors Affecting the Prognosis of Patients With Breast Cancer Combined With SPN}

Multivariate analysis showed that interval, vascular tumor thrombus, the type of SPN, and chemotherapy were all independent factors affecting the prognosis of patients with breast cancer combined with SPN $(P<0.05)$ as shown in Tables 4, 5 .

\section{DISCUSSION}

Lung metastasis is a common site of postoperative recurrence and metastasis of breast cancer. The differentiation of SPN in breast cancer patients has always been a difficult problem (8). Clinically, when looking for SPN in patients with a breast cancer history, the first thing to consider is usually the occurrence of lung metastasis from breast cancer. However, for SPN in the lung, breast cancer combined is mostly combined with PLC, and MBC or benign lung diseases are the second most important place (9). 
TABLE 5 | Multi-factor analysis of prognosis of patients with breast cancer combined with SPN.

\begin{tabular}{|c|c|c|c|c|c|c|}
\hline Factor & B & $S E$ & Walds & $P$ & OR & $95 \% \mathrm{Cl}$ \\
\hline Interval time & 2.381 & 1.053 & 5.113 & 0.031 & 10.816 & $1.373-15.190$ \\
\hline Vascular tumor thrombus & 2.195 & 0.956 & 5.272 & 0.024 & 8.980 & $1.379-9.484$ \\
\hline Maximum diameter of nodules & 1.086 & 0.734 & 2.189 & 0.298 & 2.962 & $0.702-12.486$ \\
\hline Type of SPN & 2.534 & 0.862 & 8.642 & 0.016 & 12.604 & $2.327-18.273$ \\
\hline Chemotherapy & 2.254 & 0.864 & 6.806 & 0.018 & 9.526 & $1.752-11.803$ \\
\hline
\end{tabular}

Studies have shown that compared with the normal population, breast cancer patients are more likely to be accompanied by PLC, which may be related to the common genetic factors and hormone genes of the two diseases, and has a certain correlation with the survival time of breast cancer patients (10). With the development and popularization of modern video-assisted thoracoscopy technology, the clinical diagnosis rate of SPN is increasing. Obtaining pathological diagnosis is the gold standard for clinical diagnosis. Therefore, for SPN whose nature cannot be clearly defined, it is feasible to first remove the focus and make a definite diagnosis. According to SPN, the next treatment plan includes anti-inflammation, endocrine therapy, chemotherapy, and targeted therapy $(11,12)$. Accurate identification of PLC or $\mathrm{MBC}$ in time, and determination of the next treatment plan according to the nature of SPN, is an important basis for rational clinical treatment (13).

In this study, the clinical data of patients with breast cancer complicated with PLC and MBC were retrospectively analyzed. The results showed that there were significant differences between PLC patients and MBC patients in onset age, interval, maximum nodule diameter, lymph node status, ER expression, triple negative, and radiotherapy history and so on. Compared with MBC patients, PLC patients have older onset age, longer interval and larger nodule diameter, which may be related to the preference of PLC for elderly patients, as well as the fact that some advanced MBC patients have more tumors are prone to lung metastasis $(14,15)$. Patients with negative lymph nodes, positive ER expression, less triple-negative, and more radiotherapy history are more likely to be diagnosed with PLC, which may be related to the longer survival time of these patients, and chemotherapy significantly reduces the probability of local recurrence of breast cancer $(16,17)$. Radiotherapy plays an important role in reducing local recurrence of breast cancer and increasing survival rates. Studies have shown that chemotherapy can lead to an increased incidence of Hodgkin's lymphoma complicated with lung cancer. In addition, estrogen is closely related to the occurrence of lung cancer, and many lung cancer cells are also accompanied by over-expression of ER (especially ER $\beta$ ) $(18,19)$.

Excision of the lesion can clearly diagnose the nature of SPN, so as to determine the next treatment plan in clinic, including radiotherapy, chemotherapy, and endocrine therapy (20). Among 65 PLC patients, 23 patients underwent radical lobectomy + chemotherapy + radiotherapy, 39 patients underwent wedge resection + chemotherapy, and three patients underwent radiotherapy + chemotherapy. Among $41 \mathrm{MBC}$ patients, 13 underwent wedge resection plus endocrine therapy, 21 underwent chemotherapy plus radiotherapy plus endocrine therapy, and seven underwent radiotherapy plus chemotherapy. The 5-year overall survival rate of patients with PLC was significantly higher than that of MBC patients. For breast cancer patients combined with PLC, surgical resection of lung diseases is an important means of treatment (21). For MBC patients, general palliative treatment is mainly used, and chemotherapy and endocrine therapy can effectively improve the survival rate (22). If the surgical treatment can be tolerated, whether surgical resection of solitary pulmonary metastases is meaningful to improve the quality of life and prolonging the survival time of $\mathrm{MBC}$ patients remains to be verified by prospective research results. The survival time of PLC in breast cancer is mainly determined by lung cancer. After radical resection, the clinical prognosis is good and the survival rate is high within 5 years. Once MBC appears, it is divided into the fourth stage. Even after comprehensive treatment, the prognosis is poor and the overall survival rate is significantly lower than that of breast cancer combined with PLC patients (23, 24).

The results of this study show that the curative effect of breast cancer patients with SPN was related to the interval time, the presence or absence of vascular tumor thrombus, the maximum diameter of nodules, the type of SPN, chemotherapy, and other factors. Further multivariate analysis showed that interval time, vascular tumor thrombus, SPN type, and chemotherapy were independent factors that affected the curative effect of breast cancer patients with SPN. The longer the interval between the diagnosis of breast cancer and the discovery of SPN, the PLC nature of SPN in breast cancer patients with SPN show the characteristics of better prognosis and longer survival time (25). The absence of vascular tumor thrombi and the longer survival time of patients undergoing chemotherapy may be related to the fact that the tumor load of patients is low, and chemotherapy is conducive to the removal of micro metastases throughout the body.

To sum up, compared with MBC patients, there are significant differences in the onset age, interval, maximum diameter of nodules, lymph node status, ER expression, triple negative, and radiation history among PLC patients. Septum, vascular tumor thrombus, SPN type and chemotherapy are all independent factors that affect the curative effect of breast cancer patients 
with SPN. Based on the nature of SPN, it can provide reference for clinicians to decide the treatment plan, improve patients' quality of life and prolong their survival time.

\section{DATA AVAILABILITY STATEMENT}

The original contributions presented in the study are included in the article/supplementary material, further inquiries can be directed to the corresponding author.

\section{ETHICS STATEMENT}

The studies involving human participants were reviewed and approved by the Medical Ethics Committee of Tianjin Medical University Cancer Institute and Hospital. The patients/participants provided their written informed consent to participate in this study.

\section{REFERENCES}

1. Tsang JYS, Tse GM. Molecular Classification of Breast Cancer. Adv Anat Pathol. (2020) 27:27-35. doi: 10.1097/PAP.0000000000000232

2. Cai WL, Greer CB, Chen JF, Arnal-Estapé A, Cao J, Yan Q, et al. Specific chromatin landscapes and transcription factors couple breast cancer subtype with metastatic relapse to lung or brain. BMC Med Genomics. (2020) 13:33. doi: 10.1186/s12920-020-0695-0

3. Jin L, Han B, Siegel E, Cui Y, Giuliano A, Cui X. Breast cancer lung metastasis: Molecular biology and therapeutic implications. Cancer Biol Ther. (2018) 19:858-68. doi: 10.1080/15384047.2018.1456599

4. Medeiros B, Allan AL. Molecular mechanisms of breast cancer metastasis to the lung: clinical and experimental perspectives. Int J Mol Sci. (2019) 20:2272. doi: 10.3390/ijms20092272

5. Peart O. Metastatic breast cancer. Radiol Technol. (2017) 88:519-39.

6. Liu C, Li H, Xu K, Song S, He Y, Cai X, et al. Multiple primary lung cancer versus intrapulmonary metastatic cancer: a case of multiple pulmonary nodules. Thorac Cancer. (2019) 10:352-8. doi: 10.1111/1759-7714.12918

7. Yousefi M, Nosrati R, Salmaninejad A, Dehghani S, Shahryari A, Saberi A. Organ-specific metastasis of breast cancer: molecular and cellular mechanisms underlying lung metastasis. Cell Oncol. (2018) 41:12340. doi: 10.1007/s13402-018-0376-6

8. Li K, Xu C, Du Y, Junaid M, Kaushik AC, Wei DQ. Comprehensive epigenetic analyses reveal master regulators driving lung metastasis of breast cancer. $J$ Cell Mol Med. (2019) 23:5415-31. doi: 10.1111/jcmm.14424

9. Macherey S, Mallmann P, Malter W, Doerr F, Heldwein M, Wahlers T, et al. Lung metastasectomy for pulmonary metastatic breast carcinoma. Geburtshilfe Frauenheilkd. (2017) 77:645-50. doi: 10.1055/s-0043-108252

10. Neves M, Fumagalli A, van den Bor J, Marin P, Smit MJ, Mayor F. The role of ACKR3 in 8. Mol Pharmacol. (2019) 96:819-25. doi: 10.1124/mol.118.115279

11. $\mathrm{Xu} \mathrm{H}, \mathrm{Pu} \mathrm{XH} \mathrm{Yu}$ TF, Shi $\mathrm{HB}, \mathrm{Wu} \mathrm{YL}, \mathrm{Xu} \mathrm{YM}$, et al. Incidence and natural course of CT-detected pulmonary ground-glass nodules in Chinese women with breast cancer: a retrospective, single-center, long-term follow-up study in 4682 consecutive patients. Acta Radiol. (2020) 61:17583. doi: 10.1177/0284185119856259

12. Hammer MM, Mortani Barbosa EJ Jr. Predictive factors for malignancy in incidental pulmonary nodules detected in breast cancer patients at baseline CT. Eur Radiol. (2017) 27:2802-9. doi: 10.1007/s00330-016-4627-5

13. Song Z, Ye T, Ma L, Xiang J, Chen H. Surgical outcomes of isolated malignant pulmonary nodules in patients with a history of breast cancer. Ann Surg Oncol. (2017) 24:3748-53. doi: 10.1245/s10434-017-6067-0

14. Lin S, Mo H, Li Y, Guan X, Chen Y, Wang Z, et al. Clinicopathological characteristics and survival outcomes in patients with synchronous

\section{AUTHOR CONTRIBUTIONS}

$\mathrm{LH}$ and XW were mainly responsible for the design of the study and the writing of the manuscript. XL and YJ were mainly responsible for the collection of case data. WZ and XJ were responsible for the data recording. $\mathrm{YZ}$ and $\mathrm{WM}$ were responsible for the data statistical analysis. ZT was the instructor of the whole study. All authors contributed to the article and approved the submitted version.

\section{FUNDING}

This study was supported by Key Task Project of Tianjin Health and Family Planning Commission (16KG128), Anticancer Key Technologies R\&D Program of Tianjin (12ZCDZSY16200), Natural Science Foundation of Tianjin (18JCYBJC91600), amd Scientific research program of Tianjin Education Commission (2020KJ139).

lung metastases upon initial metastatic breast cancer diagnosis in Han population. BMC Cancer. (2021) 21:1330. doi: 10.1186/s12885-021-0 9038-2

15. He KW, Wei W, Liu ZY, Song X, Zhuo PY, Ma QH, et al. [Clinicopathological features of second primary lung cancer and pulmonary metastasisin patients with breast cancer]. Zhonghua Zhong Liu Za Zhi. (2018) 40:2015. doi: 10.3760/cma.j.issn.0253-3766.2018.03.008

16. Kwapisz D. Oligometastatic breast cancer. Breast Cancer. (2019) 26:138-46. doi: 10.1007/s12282-0180921-1

17. Liu B, Xia H. Progress in Surgery for Pulmonary Metastases. Zhongguo Fei Ai Za Zhi. (2019) 22:574-8. doi: 10.3779/j.issn.1009-3419.2019.09.04

18. Xie L, Lin C, Zhang $\mathrm{H}$, Bao X. Second malignancy in young early-stage breast cancer patients with modern radiotherapy: a long-term population-based study (A STROBE-compliant study). Medicine. (2018) 97:593. doi: 10.1097/MD.00000000000 10593

19. Meng W, Liao Y, Chen J, Wang Y, Meng Y, Li K, et al. Upregulation of estrogen receptor beta protein but not mRNA predicts poor prognosis and may be associated with enhanced translation in non-small cell lung cancer: a systematic review and meta-analysis. J Thorac Dis. (2021) 13:4281300. doi: 10.21037/jtd-21-658

20. Latorzeff I, Bourgier C, Pinel B, Hennequin C, Jimenez G, Chapet O, et al. Traitement de la maladie primitive (cancers du sein, du poumon non à petites cellules et de la prostate), par irradiation, au stade d'emblée métastatique [Treatment of primary disease (breast, non-small cell lung and prostate cancers) with irradiation in case of de novo metastatic cancer]. Cancer Radiother. (2019) 23:486-95. doi: 10.1016/j.canrad.2019.08.004

21. Cruickshank A, Stieler G, Ameer F. Evaluation of the solitary pulmonary nodule. Intern Med J. (2019) 49:306-15. doi: 10.1111/imj.14219

22. Xiao W, Zheng S, Liu P, Zou Y, Xie X, Yu P, et al. Risk factors and survival outcomes in patients with breast cancer and lung metastasis: a populationbased study. Cancer Med. (2018) 7:922-30. doi: 10.1002/cam4.1370

23. Wang JC Li GY, Wang B, Han SX, Sun X, Jiang YN, et al. Metformin inhibits metastatic breast cancer progression and improves chemosensitivity by inducing vessel normalization via PDGF-B downregulation. J Exp Clin Cancer Res. (2019) 38:235. doi: 10.1186/s13046-0191211-2

24. Urooj T, Wasim B, Mushtaq S, Shah SNN, Shah M. Cancer cell-derived secretory factors in breast cancer-associated lung metastasis: their mechanism and future prospects. Curr Cancer Drug Targets. (2020) 20:168-86. doi: 10.2174/15680096206661912201 51856 
25. Chen MT, Sun HF, Zhao Y, Fu WY, Yang LP, Gao SP, et al. Comparison of patterns and prognosis among distant metastatic breast cancer patients by age groups: a SEER population-based analysis. Sci Rep. (2017) 7:9254. doi: 10.1038/s41598-017-10166-8

Conflict of Interest: The authors declare that the research was conducted in the absence of any commercial or financial relationships that could be construed as a potential conflict of interest.

Publisher's Note: All claims expressed in this article are solely those of the authors and do not necessarily represent those of their affiliated organizations, or those of the publisher, the editors and the reviewers. Any product that may be evaluated in this article, or claim that may be made by its manufacturer, is not guaranteed or endorsed by the publisher.

Copyright (c) 2022 He, Wang, Liu, Jia, Zhao, Jia, Zhu, Meng and Tong. This is an open-access article distributed under the terms of the Creative Commons Attribution License (CC BY). The use, distribution or reproduction in other forums is permitted, provided the original author(s) and the copyright owner(s) are credited and that the original publication in this journal is cited, in accordance with accepted academic practice. No use, distribution or reproduction is permitted which does not comply with these terms. 